\title{
Association of Receptor Activator of Nuclear Factor-kB Ligand (RANKL) and Osteoprotegerin with Secondary Hypogonadism in Egyptian Females with Beta-Thalassemia Major
}

\author{
Nearmeen M. Rashad ${ }^{1 *}$, Amira M. El-Helaly ${ }^{2}$, Ahmed M. Radwan ${ }^{3}$, Neveen F. Ibrahim ${ }^{1}$ \\ Departments ${ }^{1}$ Internal Medicine, ${ }^{2}$ Clinical Pathology and ${ }^{3}$ Obstetrics \& Gynecology, \\ Faculty of Medicine, Zagazig University, Sharkia, Egypt \\ *Corresponding author: Nearmeen M. Rashad, Tel.: +20 1224248642, \\ E-mail: nrashad78@yahoo.com \& n.rashad@zu.edu.eg.
}

\begin{abstract}
Background: Thalassemia is the most common cause of chronic hemolytic anemia and is correlated with significant morbidity and mortality. Osteoprotegerin (OPG) is an $\alpha$ tumor necrosis factor receptor superfamily glycoprotein that acts as a decoy receptor for the receptor activator of nuclear factor kappa B ligand (RANKL), exerting an antiresorptive bone effect and also play critical roles in hypogonadism associated osteoporosis.

Objective: To explore the serum levels of RANKL and OPG in adult Egyptian females with Beta-Thalassemia Major (BTM) and to detect their relations with female hypogonadism

Patients and Methods: a prospective cross-sectional controlled study enrolled 50 control females and 45 women with BTM. We measured OPG and RANKL by ELISA, Bone mineral density (BMD) of the lumbar spine and femoral neck was measured by dual-energy X-ray absorptiometry

Results: Among 45 patients with BTM, 27 patients had hypogonadotropic hypogonadism, and they had significantly higher values of serum RANKL $(8.3 \pm 1.8 \mathrm{pmol} / \mathrm{l})$ compared to BTM without hypogonadism $(5.9 \pm 1.01)$ and controls (5.5 \pm 1.11$)$. Regarding serum OPG, there were no non-significant differences between the studied groups. Linear regression analysis test revealed that serum RANKL levels were independently correlated with BMD femur and spine, while serum OPG levels were independently correlated with BMD spine and LH. The sensitivities and the specificities of serum RANKL levels by ROC tests to discriminate against BTM patients with hypogonadism were $91.1 \%$ and $96 \%$.
\end{abstract}

Conclusions: Serum RANK levels elevated in BTM patients particularly hypogonadism groups. The diagnostic power of serum RANKL was highly significant thus, it could be used as a biological marker of hypogonadism in BTM.

Keywords: Beta-Thalassemia Major, RANKL, OPG, hypogonadism, BMD.

\section{INTRODUCTION}

Accumulating studies have reported that the survival rate of patients with Thalassemia has increased significantly and this could be due to treatment with transfusion programs and chelating therapy, osteoporosis represents an important cause of morbidity in adult patients who display increased fracture risk ${ }^{(\mathbf{1})}$. Thalassemia is a group of genetic disorders characterized by quantitative defects in globin chain synthesis with the subsequent absence of $\mathrm{Hb}$ production leading to a variable degree of microcytic anemia ${ }^{(2)}$.

Beta-thalassemia major (BTM) is inherited in an autosomal recessive disorder. Beta-thalassemia is the most common genetically inherited hemoglobin disorder in Egypt with a carrier rate varying from 5.3 to $>9 \%{ }^{(3)}$.

Osteoporosis is the most common complication associated with Beta-thalassemia's and the etiology is multifactorial (a hormonal deficiency, bone marrow expansion, increased iron stores, desferrioxamine toxicity, and calcium and vitamin D deficiency ${ }^{(4)}$ and hypogonadism ${ }^{(5)}$.

Hypogonadism is a well- documented cause of osteoporosis and osteopenia not only in thalassemias but also in the general population and is characterized by high bone turnover ${ }^{(6)}$. stromal celland osteoblast- derived cytokines are under the control of sex hormones ${ }^{(7,8)}$, Bone resorption is reliant on receptor activator of the nuclear factor kappa $\mathrm{B}$ (NFKB) ligand (RANKL), a tumor necrosis factor (TNF) family member that is produced by osteoblasts, osteocytes, bone marrow stromal cells, and T-cells among others ${ }^{(9)}$.

Osteoprotegerin (OPG) is a multifunctional cytokine involved in the regulation of cell survival and differentiation of several cell lineages and apoptosis in normal and malignant cells and it binds RANKL and represents a decoy receptor even for TNF-related apoptosis-inducing ligand ${ }^{(10)}$. There are many evolving studies about the biological effects of the OPG/RANKL system on various metabolic bone diseases but still, the pathogenesis of bone disease in thalassemia has remained completely unknown. Thus, the objective of the current study was to explore the serum levels of RANKL and OPG in adult Egyptian females with Beta-Thalassemia Major (BTM) and to detect their relations with female hypogonadism.

\section{PATIENTS AND METHODS}


A prospective cross-sectional study enrolled 45 consecutive adult females with BTM recruited from the Outpatient Clinic of the Endocrinology Unit of Internal Medicine Department, Faculty of Medicine, Zagazig University, Egypt. Out of 45 BTM patients;27 patients had delayed puberty; hypogonadotrophic hypogonadism (Tanner stage II and III, and low levels of follicle-stimulating hormone (FSH), luteinizing hormone (LH), and estradiol (E2), and 18 female patients had full pubertal development (Tanner's stage 5) and normal levels of hormones. All BTM were regularly transfused since early childhood and underwent chelation therapy and now on a hypertransfusion regimen and combined chelation therapy with desferrioxamine $40-60 \mathrm{mg} / \mathrm{kg} 5$ days per week and deferiprone $75 \mathrm{mg} / \mathrm{kg} /$ day.

The demographic and clinical data of all the patients studied were obtained including age, height, body weight, age at first blood transfusion, age at the start of regular desferrioxamine chelation, duration of iron chelation, compliance, history of splenectomy $(\mathrm{g} / \mathrm{cm} 2)$ was assessed for all the selected participants using Prodigy-(GE Healthcare, USA).

A dual-energy X-ray absorptiometry (DEXA) was done for all patients. T-Scores were recorded following World Health Organization guidelines. Based on these criteria, women with T-Scores value higher than -1.0 were considered normal and below -1.0 were considered low BMD group.

Participants on antioxidant supplements or steroids; those with other conditions such as cancer, renal or hepatic impairment, hypothyroidism, hypocalcemia, hypoparathyroidism or diabetes, malabsorption, cardiovascular diseases; metabolic disease (Paget's disease or osteomalacia), on diuretics as well as women undergoing hormone therapy were excluded from the study.

\section{Ethics approval and consent to participate}

Written informed consent was taken from all of the participants after explaining details and benefits as well as risks to them. The ethical committee of Faculty of Medicine, Zagazig University, approved the current study.

\section{Sampling of blood}

Blood samples were drawn from all subjects during the early follicular phase of the menstrual cycles. One $\mathrm{ml}$ was collected into tubes containing fluoride for fasting plasma glucose (FPG). A second remaining part underwent immediate serum separation and was stored at $-20 \circ \mathrm{C}$ until analysis. Complete Blood Count: Serum ferritin: using Tosoh AIA1800ST (Japan) immunoassay analyzer. We determined FSH LH) and E2 were measured with chemiluminescence assays using the autoanalyzer (Abbott laboratories, Chicago, IL, USA) Determination of serum vitamin D levels using enzyme-linked immunosorbent assay, (Cat No. EQ 6411-9601, Euroimmun Medizinische Labordiagnostika AG, Germany). The serum calcium and phosphate were determined by spectrofluorometric analysis. Serum parathyroid hormone $(\mathrm{PTH})$ concentrations were measured with an autoanalyzer (Cobas 8000, ROACHE). Total cholesterol, high-density lipoprotein (HDL) cholesterol, and triglyceride levels were determined using routine enzymatic methods (Spinreact, Girona, Spain). Low-density lipoprotein (LDL) cholesterol levels were calculated using the Friedewald formula.

\section{Assessment of Serum OPG and RANKL levels}

Serum OPG and RANKL levels were measured by ELISA kits supplied from Biomedica (Vienna, Austria) were used for measurements. Intraand interassay coefficients of variation $(\mathrm{CV})$ for RANKL were less than 5\% and less than 9\%, respectively. Intra- and interassay $\mathrm{CV}$ for OPG was less than $4 \%$ and less than $8 \%$, respectively. The limit of detection was $0.08 \mathrm{pmol} / \mathrm{L}$ for RANKL and 0.14 $\mathrm{pmol} / \mathrm{L}$ for OPG. Bone mineral density was measured at the L2-4 level lumbar spine and femoral neck using dual-energy $\mathrm{x}$-ray absorptiometry by a Norland ER-35 analyzer.

\section{Statistical analysis}

Data were verified, coded by the researcher, and analyzed using IBM-SPSS Statistics for Windows, version 23.0 (Copyright IBM Corp., Armonk, N.Y., USA. 2015). Descriptive statistics: Means, standard deviations, medians, ranges, and percentages were calculated. Test of significances: chi-square test was used to compare the difference in the distribution of frequencies among different groups. For continuous variables; independent t-test analysis was carried out to compare the means of dichotomous data. There was no specific calculation of the sample size. A significant p-value was considered when it is equal to or less than 0.05 .

\section{RESULTS}

Among studied subjects ( $\mathrm{n}=95)$, we enrolled 45 female patients with BTM and their mean age was $22.5 \pm 8.683$ year. While the control group $(n=50)$, their mean age was $23.1 \pm 7.38$ years. The case and the control group were matched for age and sex

\section{Clinical and laboratory characteristics of studied subjects}

BTM patients had significantly higher values of ferritin, ALT, FT4 as well as TSH compared to the control group $(P<0.001)$. On the other hand, BTM patients had significantly lower values of BMD Spine, BMD femur, $\mathrm{LH}, \mathrm{FSH}, \mathrm{Hb}, \mathrm{E} 2$, and tanner stage compared to the control group $(\mathrm{P}<0.001)$, Table 1 . 
Table 1: Clinical and laboratory characteristics of studied subjects

\begin{tabular}{|c|c|c|c|}
\hline 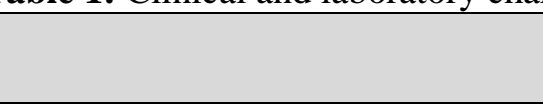 & $\begin{array}{c}\text { Control group } \\
(\mathbf{n}=50)\end{array}$ & $\begin{array}{c}\text { BTM group } \\
(n=45)\end{array}$ & P-value \\
\hline Systolic blood pressure $(\mathrm{mm} \mathrm{Hg})$ & $127.01 \pm 6.38$ & $128.0 \pm 5.58$ & 0.877 \\
\hline Diastolic blood pressure $(\mathrm{mm} \mathrm{Hg})$ & $85.77 \pm 4.41$ & $84.09 \pm 4.06$ & 0.538 \\
\hline Body mass index $(\mathrm{kg} / \mathrm{m} 2)$ & $23.32 \pm 3.96$ & $23.41 \pm 4.64$ & 0.745 \\
\hline $\begin{array}{l}\text { Amenorrhea } \\
\text { Primary } \\
\text { Secondary }\end{array}$ & $\begin{array}{l}- \\
-\end{array}$ & $\begin{array}{l}18(40 \%) \\
9(20 \%)\end{array}$ & $<0.001 *$ \\
\hline Tanner stage & 5 & $3.4 \pm 1.38$ & $<0.001^{*}$ \\
\hline BMD Spine & $-0.771 \pm 0.28$ & $-1.91 \pm 0.58$ & $<0.001^{*}$ \\
\hline BMD femur & $-0.79 \pm 0.28$ & $-1.83 \pm 0.78$ & $<0.001^{*}$ \\
\hline Total cholesterol (mg/dL) & $178.3 \pm 17.34$ & $185.91 \pm 25.33$ & 0.092 \\
\hline Triglycerides (mg/dL) & $153.3 \pm 15.8$ & $152.46 \pm 16.22$ & 0.087 \\
\hline LDL cholesterol (mg/dL) & $123.05 \pm 19.6$ & $121.46 \pm 0.81$ & 0.086 \\
\hline HDL cholesterol (mg/dL) & $57.32 \pm 6.7$ & $54.35 \pm 6.5$ & 0.051 \\
\hline Fasting blood glucose (mg/dL) & $88.32 \pm 5.7$ & $87.35 \pm 7.5$ & 0.787 \\
\hline Serum calcium $(\mathrm{mmol} / \mathrm{L})$ & $9.3 \pm 0.5$ & $9.1 \pm 0.5$ & 0.478 \\
\hline Phosphate $\left(\mathrm{PO}_{4}\right)(\mathrm{mmol} / \mathrm{L})$ & $4.2 \pm 0.21$ & $4.3 \pm 0.11$ & 0.479 \\
\hline PTH (ng/ml) & $41.32 \pm 2.55$ & $39.35 \pm 2.11$ & 0.274 \\
\hline FSH (mIU/mL) & $5.32 \pm 1.47$ & $3.35 \pm 0.35$ & $<0.001^{*}$ \\
\hline $\mathrm{LH}(\mathrm{mIU} / \mathrm{mL})$ & $6.82 \pm 1.73$ & $4.2 \pm 0.55$ & $<0.001^{*}$ \\
\hline $25(\mathrm{OH}) \mathrm{D}(\mathrm{nmol} / \mathrm{l}$ & $38.42 \pm 3.254$ & $36.54 \pm 4.33$ & 0.274 \\
\hline $\mathrm{E} 2(\mathrm{pg} / \mathrm{ml})$ & $39.9 \pm 2.51$ & $24.5 \pm 5.9$ & $<0.001 *$ \\
\hline $\mathrm{Hb}(\mathrm{mg} / \mathrm{dl})$ & $12 \pm 1.21$ & $9.4 \pm 1.59$ & $<0.001^{*}$ \\
\hline Albumin $(\mathrm{g} / \mathrm{dl}) 0$ & $4.8 \pm 0.31$ & $4.01 \pm 0.39$ & $<0.001^{*}$ \\
\hline ALT (IU/liter) & $17.8 \pm 3.91$ & $32.7 \pm 0.59$ & $<0.001^{*}$ \\
\hline FT4(ng/dl) & $1.29 \pm 0.21$ & $2.04 \pm 0.59$ & $<0.001^{*}$ \\
\hline TSH $(\mu \mathrm{IU} / \mathrm{ml})$ & $2.44 \pm 0.16$ & $3.24 \pm 0.420$ & $<0.001^{*}$ \\
\hline Prolactin $(\mathrm{ng} / \mathrm{mL})$ & $12.3 \pm 2.21$ & $12.29 \pm 1.34$ & 0.542 \\
\hline Ferritin & $46.9 \pm 2.21$ & $1740 \pm 75.9$ & $<0.001^{*}$ \\
\hline OPG (pmol/liter) & $3.11 \pm 0.78$ & $3.14 \pm 0.52$ & 0.264 \\
\hline RANKL (pmol/liter) & $5.5 \pm 1.11$ & $8.5 \pm 1.88$ & $<0.001^{*}$ \\
\hline OPG/ RANKL & $0.725 \pm 0.15$ & $0.329 \pm 0.04$ & $<0.001^{*}$ \\
\hline
\end{tabular}

E2,estradiol;Hb,haemoglobin;PTH, parathyroid hormone ;25(OH) D, 25-hydroxycholecalciferol; HDL-C, highdensity lipoprotein-cholesterol; LDL-C, low-density lipoprotein; ALT , alanine aminotransferase ;TSH, thyroid stimulating hormone; FT4, free thyroxine; RANKL, receptor activator of nuclear factor-kB ligand ;OPG ,Osteoprotegerin. $* \mathrm{P}<0.05$

\section{General characteristics of BTM patients.}

Among BTM patients, 27 patients had hypogonadotropic hypogonadism diagnosed clinically by amenorrhea (18 had primary and 9 had secondary), mean tanner stage(3.4 \pm 1.38$)$ and there were statistically significant lower values of LH, FSH, E2 compared to BTM without hypogonadism $(n=18)$ On the other hand, BTM patients with hypogonadism had significantly higher values of ferritin compared to BTM without hypogonadism $(\mathrm{P}<0.001)$, Table 2.

\section{Comparison of serum RANKL and OPG levels in the studied groups.}

Our results show that BMT with hypogonadism had significantly higher values of serum RANKL (pmol/liter) $(8.3 \pm 1.8)$ compared to BTM without hypogonadism (5.9 \pm 1.01$)$ and controls (5.5 \pm 1.11$), \mathrm{P}<0.001$

Regarding serum OPG (pmol/liter), there were non-significant differences between the studied group; BMT with hypogonadism (3.28 \pm 0.81 , BTM without hypogonadism $(3.39 \pm 0.21)$ and controls (3.11 \pm 0.52$), \mathrm{P}<0.001$. 
Table 2: Clinical and laboratory characteristics of BTM groups

\begin{tabular}{|c|c|c|c|}
\hline Variable & $\begin{array}{c}\text { BTM without } \\
\text { hypogonadism }(n=18)\end{array}$ & $\begin{array}{c}\text { BTM with } \\
\text { hypogonadism }(n=27)\end{array}$ & P-value \\
\hline Age (years) & $21.51 \pm 7.78$ & $23.5 \pm 8.18$ & 0.524 \\
\hline Systolic blood pressure $(\mathrm{mm} \mathrm{Hg})$ & $125.01 \pm 5.38$ & $127.2 \pm 4.58$ & 0.060 \\
\hline Diastolic blood pressure $(\mathrm{mm} \mathrm{Hg})$ & $85.87 \pm 3.51$ & $87.09 \pm 4.26$ & 0.100 \\
\hline Body mass index $(\mathrm{kg} / \mathrm{m} 2)$ & $23.52 \pm 1.96$ & $23.21 \pm 1.64$ & 0.690 \\
\hline $\begin{array}{l}\text { Amenorrhea } \\
\text { Primary } \\
\text { Secondary }\end{array}$ & $\begin{array}{l}- \\
-\end{array}$ & $\begin{array}{l}18(40 \%) \\
9(20 \%)\end{array}$ & $<0.001^{*}$ \\
\hline Tanner stage & 5 & $3.4 \pm 1.38$ & 0.754 \\
\hline BMD Spine & $-1.90 \pm 0.38$ & $-1.94 \pm 0.68$ & 0.917 \\
\hline BMD femur & $-1.81 \pm 0.48$ & $-1.87 \pm 0.88$ & 0.920 \\
\hline Total cholesterol $(\mathrm{mg} / \mathrm{dL})$ & $177.3 \pm 11.34$ & $179.91 \pm 22.3$ & 0.804 \\
\hline Triglycerides $(\mathrm{mg} / \mathrm{dL})$ & $151.22 \pm 20.8$ & $153.36 \pm 24.2$ & 0.765 \\
\hline LDL cholesterol (mg/dL) & $107.05 \pm 19.6$ & $122.46 \pm 15.8$ & 0.009 \\
\hline HDL cholesterol (mg/dL) & $55.82 \pm 2.7$ & $54.55 \pm 6.5$ & 0.436 \\
\hline Fasting blood glucose $(\mathrm{mg} / \mathrm{dL})$ & $86.32 \pm 5.7$ & $87.35 \pm 7.5$ & 0.456 \\
\hline Serum calcium $(\mathrm{mmol} / \mathrm{L})$ & $9.1 \pm 0.5$ & $8.9 \pm 0.5$ & 0.070 \\
\hline Phosphate $\left(\mathrm{PO}_{4}\right)(\mathrm{mmol} / \mathrm{L})$ & $4.4 \pm 0.21$ & $4.1 \pm 0.61$ & 0.165 \\
\hline PTH $(\mathrm{ng} / \mathrm{ml})$ & $39.32 \pm 2.23$ & $40.35 \pm 2.32$ & 0.052 \\
\hline FSH (mIU/mL) & $5.72 \pm 1.47$ & $2.35 \pm 0.35$ & $<0.001^{*}$ \\
\hline $\mathrm{LH}(\mathrm{mIU} / \mathrm{mL})$ & $7.12 \pm 1.73$ & $2.2 \pm 0.55$ & $<0.001^{*}$ \\
\hline $25(\mathrm{OH}) \mathrm{D}(\mathrm{nmol} / \mathrm{l}$ & $37.32 \pm 3.7$ & $36.7 \pm 4.5$ & 0.062 \\
\hline $\mathrm{E} 2(\mathrm{pg} / \mathrm{ml})$ & $33.2 \pm 6.51$ & $18.8 \pm 2.9$ & $<0.001^{*}$ \\
\hline $\mathrm{Hb}(\mathrm{mg} / \mathrm{dl})$ & $9.7 \pm 1.41$ & $9.1 \pm 0.89$ & 0.397 \\
\hline Albumin $(\mathrm{g} / \mathrm{dl}) 0$ & $4.2 \pm 0.31$ & $4.4 \pm 0.39$ & 0.446 \\
\hline ALT (IU/liter) & $32.9 \pm 1.1$ & $33.11 \pm 5.5$ & 0.917 \\
\hline FT4(ng/dl) & $1.29 \pm 0.21$ & $2.04 \pm 0.59$ & 0.446 \\
\hline $\mathrm{TSH}(\mu \mathrm{IU} / \mathrm{ml})$ & $2.44 \pm 0.16$ & $3.24 \pm 0.420$ & 0.451 \\
\hline Prolactin $(\mathrm{ng} / \mathrm{mL})$ & $11.8 \pm 0.77$ & $12.43 \pm 1.88$ & 0.051 \\
\hline Ferritin & $1557.9 \pm 34.1$ & $1895 \pm 27.9$ & $<0.001^{*}$ \\
\hline OPG (pmol/liter) & $3.39 \pm 0.21$ & $3.28 \pm 0.81$ & 0.543 \\
\hline RANKL (pmol/liter) & $5.9 \pm 1.01$ & $8.3 \pm 1.8$ & $<0.001^{*}$ \\
\hline OPG/ RANKL & $0.6 \pm 0.01$ & $0.4 \pm 0.02$ & $<0.001 *$ \\
\hline
\end{tabular}

BTM, Beta-Thalassemia Major ;E2,estradiol;Hb,haemoglobin;PTH, parathyroid hormone ;25(OH) D, 25hydroxycholecalciferol; HDL-C, high-density lipoprotein-cholesterol; LDL-C, low-density lipoprotein; ALT , alanine aminotransferase ; TSH, thyroid stimulating hormone; FT4, free thyroxine; RANKL, receptor activator of nuclear factor- $\mathrm{kB}$ ligand; OPG, Osteoprotegerin. * $\mathrm{P}<0.05$

Pearson correlation coefficient between serum RANKL and OPG levels with clinical and laboratory characteristics of BTM patients

The current results demonstrated significant negative correlations between serum RANKL and OPG levels with E2, FSH, LH, Hb as well as BMD Spine and femur. On the contrary, there was a significant positive correlation with serum ferritin levels (Table 3 ). 
Table 3: Pearson correlation coefficient between serum RANKL and OPG levels with clinical and laboratory characteristics of BTM patients

\begin{tabular}{|l|c|c|c|c|}
\hline \multirow{2}{*}{} & \multicolumn{4}{|c|}{ BTM group (n=45) } \\
\cline { 2 - 5 } & \multicolumn{2}{|c|}{ Serum RANKL } & \multicolumn{2}{c|}{ Serum OPG } \\
\cline { 2 - 5 } & $\mathbf{r}$ & $\mathbf{P}$ & $\mathbf{r}$ & P-value \\
\hline BMD Spine & -0.627 & $<0.001^{*}$ & -0.309 & $<0.001^{*}$ \\
\hline BMD femur & -0.543 & $<0.001^{*}$ & -0.454 & $<0.001^{*}$ \\
\hline PTH & -0.108 & 0.261 & -0.080 & 0.579 \\
\hline FSH & -0.764 & $<0.001^{*}$ & -0.425 & $<0.001^{*}$ \\
\hline LH & -0.839 & $<0.001^{*}$ & 0.525 & $<0.001^{*}$ \\
\hline 25(OH) D & 0.109 & 0.257 & 0.133 & 0.358 \\
\hline E2 & -0.122 & 0.203 & -0.491 & $<0.001^{*}$ \\
\hline Hb & -0.204 & $<0.001^{*}$ & -0.307 & $<0.001^{*}$ \\
\hline Albumin & 0.005 & 0.976 & 0.206 & 0.175 \\
\hline ALT & 0.065 & 0.067 & 0.183 & 0.229 \\
\hline FT4 & 0.022 & 0.884 & 0.205 & 0.167 \\
\hline TSH & 0.045 & 0.776 & 0.123 & 0.415 \\
\hline Ferritin & 0.238 & $<0.001^{*}$ & 0.282 & $<0.001^{*}$ \\
\hline Serum calcium & 0.041 & 0.667 & 0.132 & 0.413 \\
\hline Phosphate & 0.039 & 0.793 & 0.043 & 0.780 \\
\hline
\end{tabular}

Linear regression analyses in BTM patients to assess the main independent parameters associated with serum RANKL and $O P G$ levels.

Linear regression analysis test revealed that serum RANKL levels were independently correlated with BMD femur and spine $(\mathrm{p}<0.001)$, while serum OPG levels were independently correlated with BMD spine and LH ( $<<$ $0.001)$ Table 4.

Table 4: linear regression analyses test the influence of the main independent variables against serum RANKL and OPG levels (dependent variable) in patients with BTM.

\begin{tabular}{|c|c|c|c|c|c|c|c|c|c|}
\hline \multirow[b]{2}{*}{ Model } & & \multirow{2}{*}{$\begin{array}{c}\text { Unstandardized } \\
\text { Coefficients } \\
\text { B } \\
\end{array}$} & \multirow[b]{2}{*}{ S.E } & & \multirow{2}{*}{$\begin{array}{c}\begin{array}{c}\text { Standardized } \\
\text { Coefficients }\end{array} \\
\text { Beta }\end{array}$} & \multirow[b]{2}{*}{$\mathrm{t}$} & \multirow[b]{2}{*}{$\begin{array}{c}\mathrm{P} \\
\text { value }\end{array}$} & \multicolumn{2}{|c|}{ 95\% C.I. } \\
\hline & & & & & & & & $\begin{array}{c}\text { Lower } \\
\text { ound }\end{array}$ & $\begin{array}{l}\text { Upper } \\
\text { Bound }\end{array}$ \\
\hline \multirow[t]{8}{*}{ RANKL } & (Constant) & 10.413 & 3.263 & & 3.191 & 0.003 & 3.801 & 17.024 & 1.239 \\
\hline & FSH & -0.007 & 0.128 & -0.009 & -.058 & 0.954 & -0.267 & .252 & 0.004 \\
\hline & LH & -0.272 & 0.169 & -0.152 & -1.611 & 0.116 & $0-.613$ & .070 & 0.003 \\
\hline & E2 & -0.583 & 0.248 & -0.456 & -2.348 & 0.024 & -1.086 & -.080 & 0.036 \\
\hline & BMD femur & 1.116 & 0.525 & 0.492 & 2.125 & 0.040 & 0.042 & 2.181 & 0.019 \\
\hline & Prolactin & 0.255 & 0.492 & 0.076 & 0.519 & 0.607 & -0.741 & 1.252 & 0.018 \\
\hline & BMD Spine & 8.902 & 0.000 & 0.037 & 0.358 & 0.723 & 0.000 & .001 & 0.004 \\
\hline & Ferritin & 0.018 & 0.074 & 0.033 & 0.244 & 0.809 & -0.133 & .169 & 0.184 \\
\hline \multirow[t]{8}{*}{$\mathrm{OPG}$} & (Constant) & 3.215 & 1.308 & & 2.457 & 0.019 & 0.564 & 5.867 & 4.017 \\
\hline & FSH & 0.044 & 0.051 & 0.111 & 0.860 & 0.395 & -0.060 & 0.148 & 0.013 \\
\hline & LH & -0.173 & 0.068 & -0.208 & -2.563 & 0.015 & -0.310 & -.036 & 0.014 \\
\hline & E2 & 0.128 & 0.100 & 0.216 & 1.289 & 0.206 & -0.073 & 0.330 & 0.227 \\
\hline & BMD femur & -0.340 & 0.211 & -0.322 & -1.615 & 0.115 & -0.767 & 0.087 & 0.077 \\
\hline & BMD Spine & 0.915 & 0.197 & 0.582 & 4.638 & 0.000 & 0.515 & 1.314 & 0.085 \\
\hline & Prolactin & 0.000 & 0.000 & 0.136 & 1.537 & 0.133 & 0.000 & 0.000 & 0.018 \\
\hline & Ferritin & -0.002 & 0.030 & -0.008 & -0.066 & 0.948 & -0.062 & 0.059 & 0.849 \\
\hline
\end{tabular}


The accuracy of serum RANKL levels (pmol/liter) as diagnostic biomarker by ROC analysis

We investigated the potential diagnostic value of serum RANKL levels by ROC tests (Fig. 2). When we discriminate BTM patients from the control group, the cutoff values were (4.25) and the AUC was 0.966 (95\% CI $=0.926-0.999)$. Additionally, the sensitivities and the specificities were $97.8 \%$ and $92 \%(\mathrm{p}<0.001)$, figure $1 \mathrm{a}$. Among BTM patients, the potential value of serum RANKL levels in diagnosis hypogonadism was with cutoff values were (4.61) and the AUC were 0.903 (95\% CI $=0.828-0.976)$. Additionally, the sensitivities and the specificities were $91.1 \%$ and $96 \%(\mathrm{p}<0.001)$, figure $1 \mathrm{~b}$.

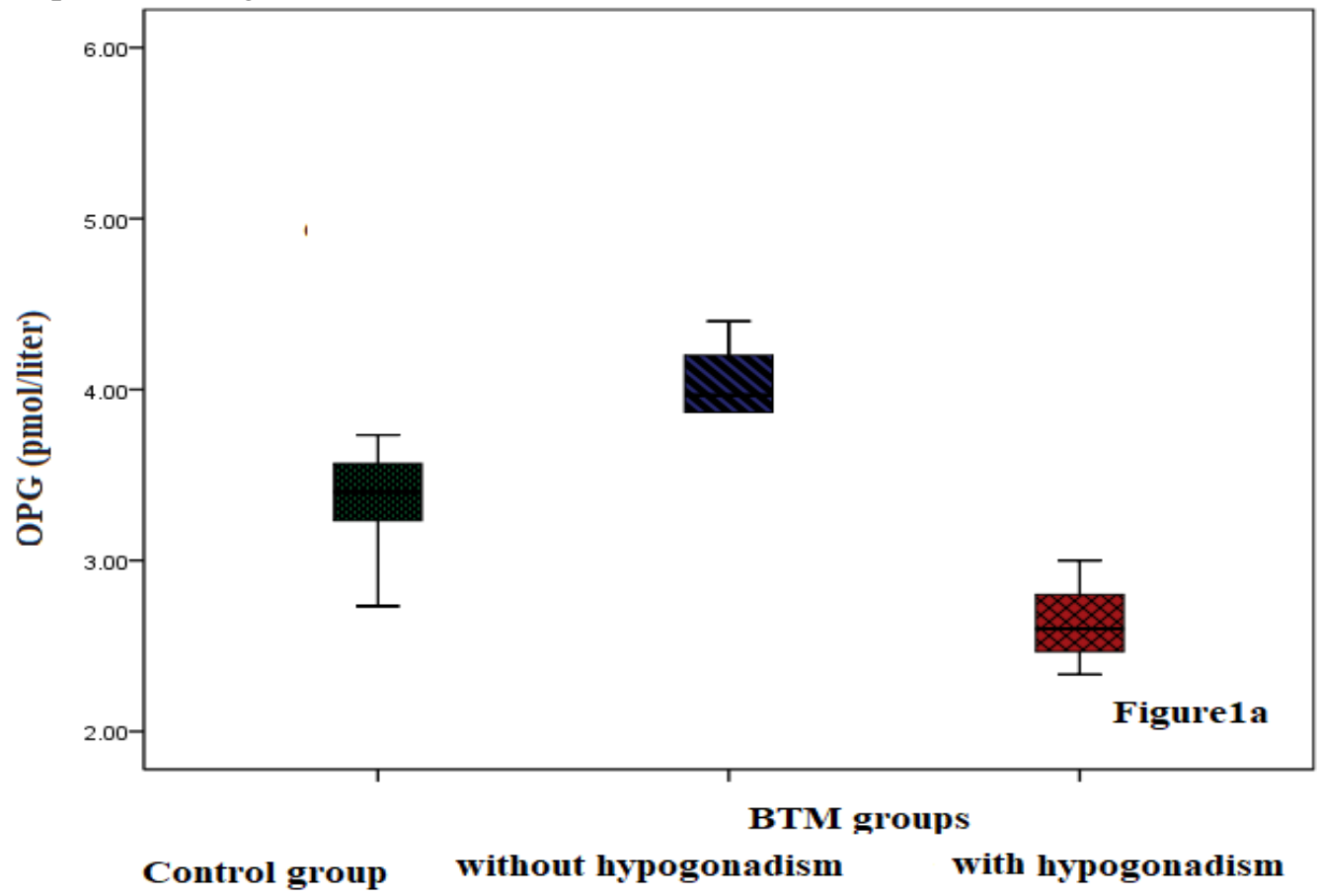

Figure 1a: Comparison of serum OPG levels in the studied groups

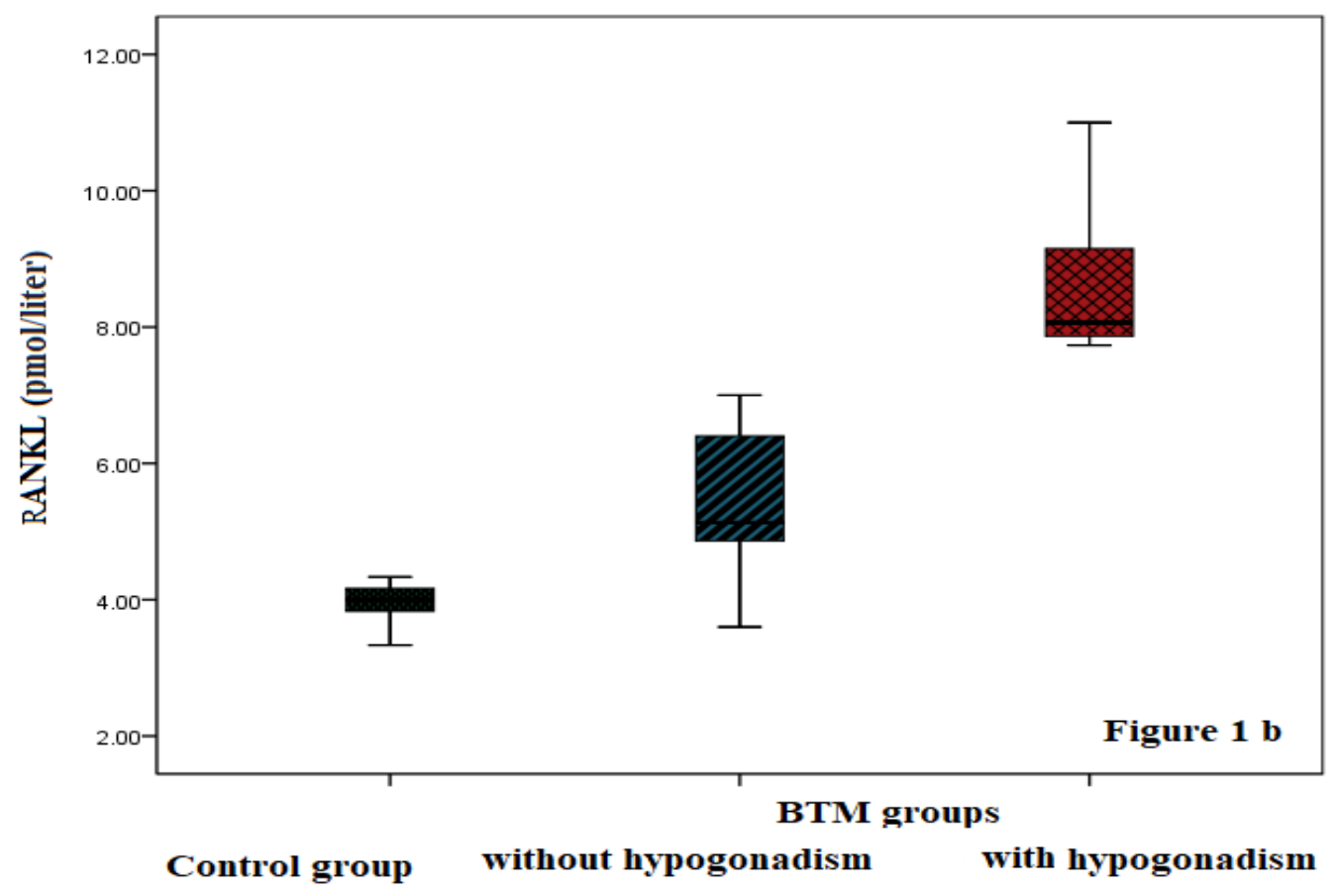

Figure 1b: Comparison of serum RANKL levels in the studied groups 


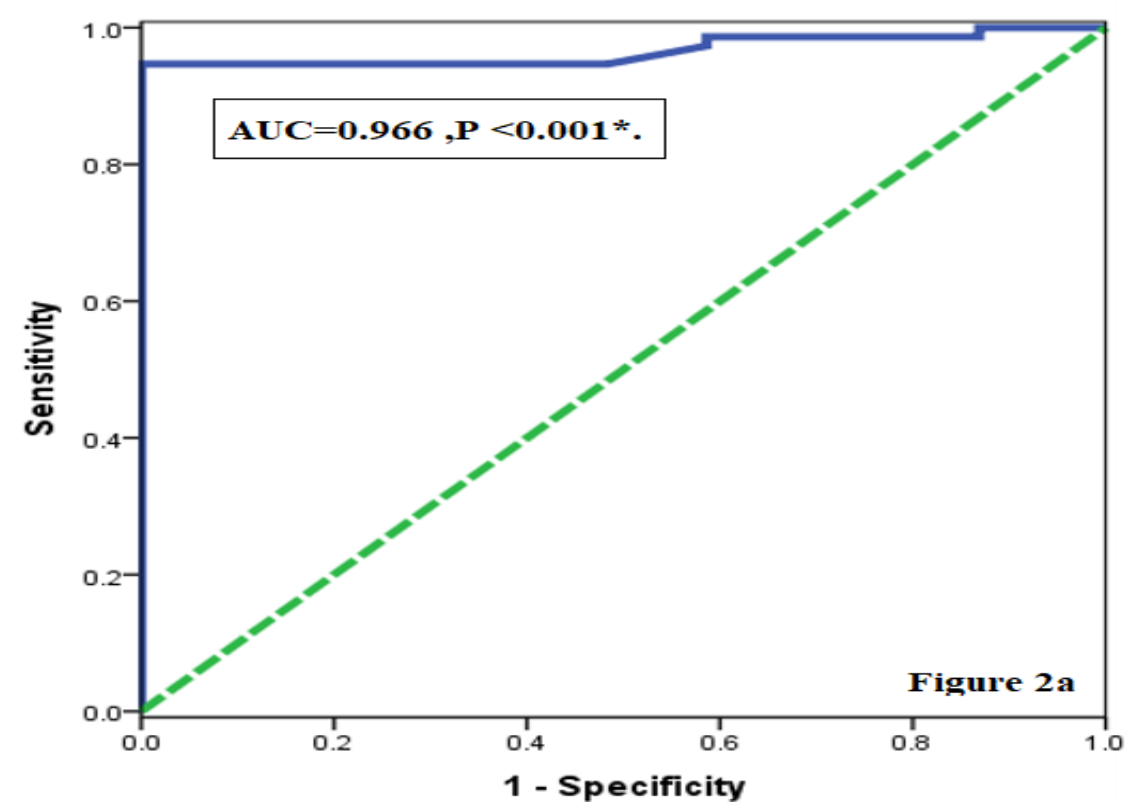

Figure 2a: Receiver operating characteristic (ROC) curve of serum RANKL to differentiate BTM patients from control

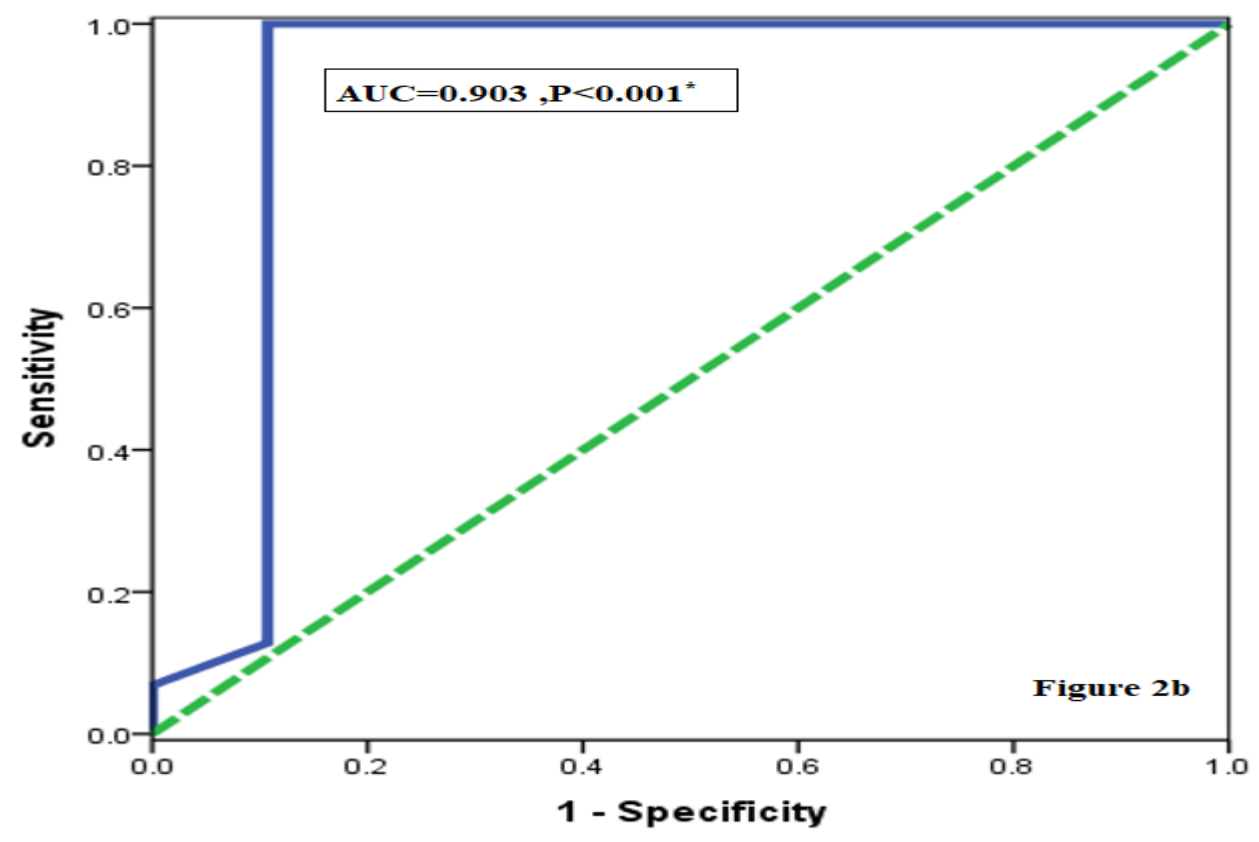

Figure 2b: Receiver operating characteristic (ROC) curve of serum RANKL to differentiate BTM patients with hypogonadism from the others without hypogonadism.

The accuracy of serum OPG levels (pmol/liter) as diagnostic biomarker by ROC analysis

We investigated the potential diagnostic value of serum OPG levels by ROC tests When we discriminate BTM patients from the control group, the cutoff values were (3.012) and the AUC was 0.843 (95\% CI $=0.723-0.962$ ). Additionally, the sensitivities and the specificities were $85.2 \%$ and $73.1 \%(\mathrm{p}<0.001)$. Among BTM patients, there was a non-significant value of serum OPG levels in diagnosis hypogonadism was with cutoff values were (3.316) and the AUC was $0.574(95 \% \mathrm{CI}=0.431-0.718)$. Additionally, the sensitivities and the specificities were $57.8 \%$ and $68 \%(\mathrm{p}<0.001)$. 


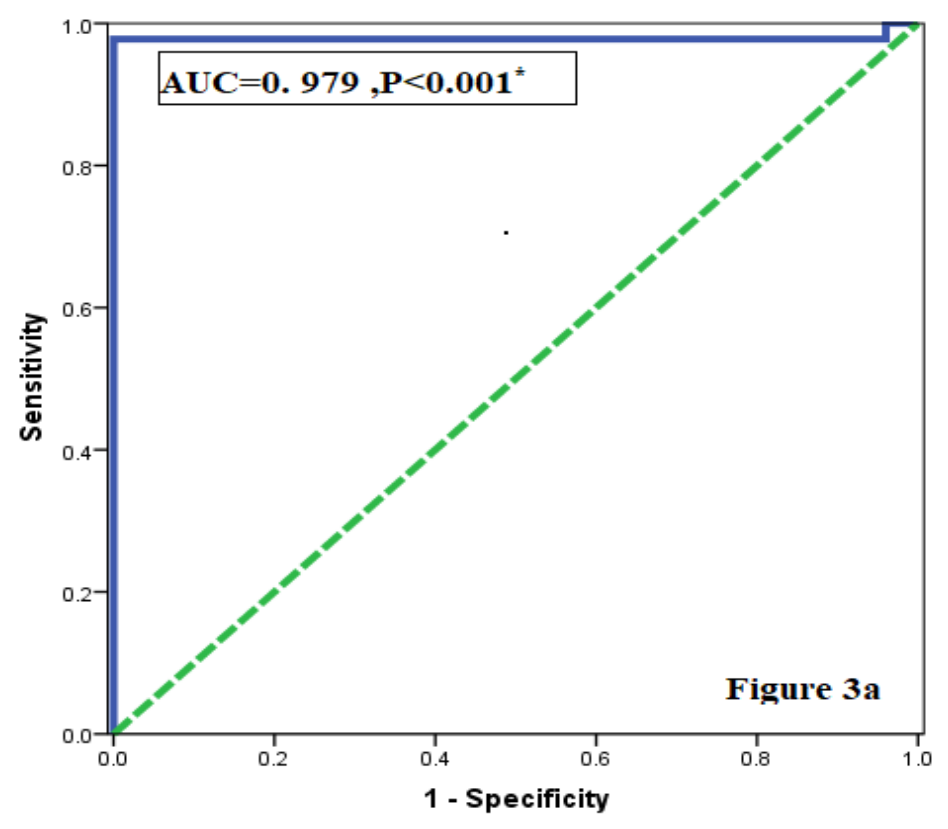

Figure 3a: Receiver operating characteristic (ROC) curve of serum OPG to differentiate BTM patients from control

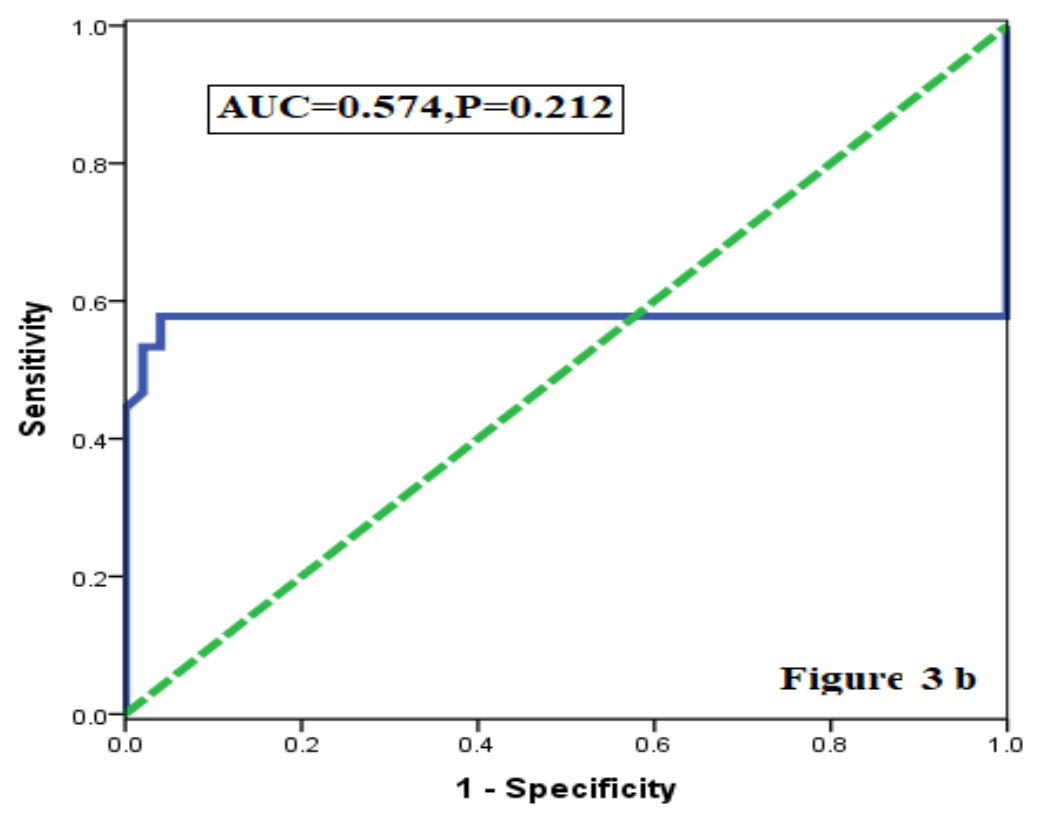

Figure 3b: Receiver operating characteristic (ROC) curve of serum OPG to differentiate BTM patients with hypogonadism from the others without hypogonadism

\section{DISCUSSION}

A preponderance of evidence suggests that thalassemia is the most common cause of chronic hemolytic anemia in Egypt. BTM correlated with significant morbidity and mortality. Osteopenia and osteoporosis are still prevalent in patients with BTM (40-80\%) despite significant improvement in ironchelation therapy ${ }^{(\mathbf{1 1}, \mathbf{1 2})}$.
Intriguing reports are investigating the pathogenesis of osteoporosis in BTM and still not known the cause of osteoporosis in BTM. A growing body of evidence has corroborated that important factors implicated in the reduction of bone mass in BTM include: Delayed puberty, growth delay, parathyroid gland dysfunction, diabetes, hypothyroidism, ineffective hemopoiesis with progressive marrow expansion, direct iron 
toxicity on osteoblasts, as well as "toxic effect" of chelating therapy have been indicated as possible etiological factors ${ }^{(\mathbf{1 3}, \mathbf{1 4})}$. OPG is an $\alpha$ tumor necrosis factor receptor superfamily glycoprotein that acts as a decoy receptor for the RANKL, exerting an antiresorptive bone effect and also play critical roles in hypogonadism associated osteoporosis. Substantial evidence implicate hypogonadism as a critical mediator in the pathophysiology of osteoporosis. Hypogonadism is the most frequently reported endocrine complication, affecting $40 \%-80 \%$ of BTM with enhanced RANKL activity ${ }^{(15,16)}$. In the current study, we aimed to explore the serum levels of RANKL and OPG in adult Egyptian females with BTM and to detect their relations with female hypogonadism.

Our study found that BTM patients had significantly higher values of ferritin, ALT, FT4 as well as TSH compared to the control group. Even more importantly, BTM patients had significantly lower values of BMD Spine, BMD femur, LH, FSH, $\mathrm{Hb}$, E2, and tanner stage compared to the control group Kyriakou et al. ${ }^{(\mathbf{1 3})}$ detected that osteoporosis was more common in hypogonadal patients compared to eugonadal.

Yassin et al. ${ }^{(17)}$ confirmed that hypogonadism, a common finding in BTM as sex steroid hormones, androgens, and estrogens, via their respective nuclear receptors, regulate BMD in humans and mice.

According to the results of the current study, among BTM patients, 27 patients had hypogonadotropic hypogonadism. Moreover, BTM patients with hypogonadism had statistically significant lower values of $\mathrm{LH}, \mathrm{FSH}, \mathrm{E} 2$ compared to BTM without hypogonadism $(n=18)$. On the other hand, BTM patients with hypogonadism had significantly higher values of ferritin compared to BTM without hypogonadism.

Similar to our findings, De Sanctis et al. ${ }^{(18)}$ observed acquired hypogonadotropic hypogonadism in adult patients with BTM. Interestingly, Vullo et al. (19) reported that hemosiderosis of the gonadotroph cells leads to hypogonadotropic hypogonadism and this damage rarely is reversible, in another study conducted by Chatterjee $\boldsymbol{e t}$ al. ${ }^{(20)}$ the gonadotropin reserve is diminished with intact gonadotropin pulse but later, the gonadotropin reserve significantly diminishes, with markedly reduced spontaneous pulsatile gonadotropin activity which may lead to irreversible damage of the H-P-G axis.

In agreement with our results, Shalitin et al. (21) detected that a high serum ferritin level during puberty (> 2,500 ng/mL) was a risk factor for hypogonadism and a serum ferritin level of $>3,000$ $\mathrm{ng} / \mathrm{mL}$, during the first decade of life is a predictor of short adult stature. Michael et al. ${ }^{(22)}$ detected that the inhibitory effect of E2 is associated with the stimulated secretion of OPG by osteoblast- derived osteosarcoma cells.

The results presented herein are innovative; as this study performs a robust estimation of serum RANKL and OPG levels in BTM patients. Our study revealed that that BMT with hypogonadism had significantly higher values of serum RANKL compared to BTM without hypogonadism and controls. Regarding serum OPG, there were no nonsignificant differences between the studied group; BMT with hypogonadism BTM without hypogonadism and controls.

Similar results were described in previous studies conducted by Pepene $\boldsymbol{e t}$ al. ${ }^{\left({ }^{(16)} \text { Compared with }\right.}$ controls, both OPG and sRANKL serum levels were increased in men with late-onset hypogonadism; however, when expressed as a ratio, sRANKL/OPG, the two groups were not significantly different.

Similar to our results Nicholas et al. (23) observed that bone turnover was significantly increased in thalassemic patients compared to controls but OPG was significantly higher in healthy subjects.

According to Pietrapertosa et al. (15), thalassemic patients had significantly higher serum levels of OPG than the controls, while their higher RANKL levels, were at the threshold of significance. The OPG/RANKL ratio showed a higher level of respect to the controls.

To the best of our knowledge, this study is the first study had explored the correlation between serum RANKL and OPG levels with a marker of hypogonadism. Noteworthy, our results confirmed that significant negative correlations between serum RANKL and OPG levels with E2, FSH, LH, Hb as well as BMD Spine and femur. On the contrary, there was a significant positive correlation with serum ferritin levels. For further evaluation, a linear regression analysis test revealed that serum RANKL levels were independently correlated with BMD femur and spine, while serum OPG levels were independently correlated with BMD spine and LH.

The study conducted by Pietrapertosa $\boldsymbol{e t}$ al . (15) observed that in thalassemic patients BMD values negatively correlated with urine markers of bone resorption but not with OPG/sRANKL system.

A similar result was observed by Jensen $\boldsymbol{e t}$ al. (24) study who found an association between hypo gonadotrophic hypogonadism and osteoporosis in adult patients with TM.

We investigated the potential diagnostic value of serum RANKL levels by ROC tests to discriminate BTM patients from the control group, the sensitivities, and the specificities were $97.8 \%$ and $92 \%$. Among BTM patients, the potential value of serum RANKL levels in diagnosis hypogonadism had sensitivities and specificities (91.1\% and 96\%). Regarding serum OPG levels, to discriminate BTM patients from the control group, the sensitivities and the specificities were 
$85.2 \%$ and $73.1 \%$. Among BTM patients, the potential value of serum RANKL levels in diagnosis hypogonadism had sensitivities and specificities $(57.8 \%$ and $68 \%)$.

\section{CONCLUSIONS}

BMT with hypogonadism had significantly higher values of serum RANKL compared to BTM without hypogonadism and controls. Regarding serum OPG, there was a non-significant difference between the studied group. Thus, serum RANKL could be used as a biological marker of hypogonadism in patients with BTM. Further future multicenter studies with a bigger sample size are needed to validate our findings.

\section{REFERENCES}

1. Ruggiero L, De Sanctis V (1998): Multicentre study on the prevalence of fractures in transfusiondependent thalassemia patients. J Pediatr Endocrinol Metab., 11: 773-778.

2. Setting A, Al-Haggar $M$, Neamatallah $M$ et al. (2006): Detection of beta-thalassemia mutations using primer-specific amplification compared to the reversed dot blot hybridization technique in Egyptian cases. Hema., 9(3): p. 401-409.

3. National Heart and Blood Institute (2014): What Are Thalassemias? Health Topics 2013 (cited 20147 Dec); Blood Diseases and Disorders). Available from: http://www.nhlbi.nih.gov / health / health topics topics / thalassemia

4. Lasco A, Morabito N, Gaudio A et al. (2002): Osteoporosis and beta- thalassemia major: Role of the IGF- I/IGFBP- III axis. Endocrinol Invest., 25: 338344.

5. Anapliotou M, Kastanias I, Psara P et al. (1995): The contribution of hypogonadism to the development of osteoporosis in thalassemia major: New therapeutic approaches. Clin Endocrinol (Oxf), 42: 279- 287.

6. Riggs B, Khosla S, Melton L (1998): A unitary model for involutional osteoporosis: estrogen deficiency causes both types I and type II osteoporosis in postmenopausal women and contributes to bone loss in aging men. J Bone Miner Res., 13: 763- 773.

7. Pacifici R (1996): Estrogen, cytokines, and pathogenesis of postmenopausal osteoporosis. J Bone Miner Res., 11: 1043- 1051.

8. Spelsberg T, Subramaniam M, Riggs B et al. (1999): The actions and interactions of sex steroids and growth factors/cytokines on the skeleton. Mol Endocrinol., 13: 819-828.

9. Yasuda H, Shima N, Nakagawa $\mathbf{N}$ et al. (1998): Osteoclast differentiation factor is a ligand for osteoprotegerin/osteoclastogenesis-inhibitory factor and is identical to TRANCE/RANKL. Proc Natl Acad Sci USA., 95:3597-602.
10. Leibbrandt A, Penninger J (2011): TNF conference 2009: beyond bones - RANKL/RANK in the immune system. Adv Exp Med Biol., 691:5-22.

11. Baldini M, Forti S, Marcon A et al. (2010): Endocrine and bone disease inappropriately treated adult patients with beta-thalassemia major. Ann Hematol., 89:1207-13.

12. Scacchi M, Danesi L, Cattaneo A et al. (2008): Bone demineralization in adult thalassaemic patients: Contribution of GH and IGF-I at different skeletal sites. Clin Endocrinol (Oxf), 69:202-7.

13. Kyriakou A, Savva S, Savvides I et al. (2008): Gender differences in the prevalence and severity of bone disease in thalassemia. Pediatr Endocrinol Rev., 6(1):116-22.

14. Voskaridou E, Terpos E (2008): Pathogenesis and management of osteoporosis in thalassemia. Pediatr Endocrinol Rev., 6(1):86-93.

15. Pietrapertosa A, Minenna G, Colella S et al. (2009): Osteoprotegerin and RANKL in the pathogenesis of osteoporosis in patients with thalassemia major. Panminerva Med., 51:17-23.

16. Pepene C, Crişan N, Coman I (2011): Elevated serum receptor activator of nuclear factor kappa $\mathrm{B}$ ligand and osteoprotegerin levels in late-onset male hypogonadism. Clin Invest Med., 34:232-38.

17. Yassin M, Soliman A, De Sanctis V et al. (2014): Effects of the anti-receptor activator of nuclear factor kappa B ligand denosumab on beta-thalassemia majorinduced osteoporosis. Indian J Endocrinol Metab., 18(4):546- 551.

18. De Sanctis V, Elsedfy H, Soliman A et al. (2016): Acquired hypogonadotropic hypogonadism $(\mathrm{AHH})$ in thalassemia major patients: An underdiagnosed condition? Mediterr J Hematol Infect Dis., 8(1):2016001.

19. Vullo C, De Sanctis V, Katz M et al. (1990): Endocrine abnormalities in thalassemia. Ann N Y Acad Sci., 612:293-310.

20. Chatterjee R, Katz M, Cox T et al. (1993): Prospective study of the hypothalamic-pituitary axis in thalassaemic patients who developed secondary amenorrhoea. Clin Endocrinol (Oxf), 39:287-296.

21. Shalitin S, Carmi D, Weintrob N et al. (2005): Serum ferritin level as a predictor of impaired growth and puberty in thalassemia major patients. Eur J Haematol., 74:93-100.

22. Michael H, Härkönen $P$, Väänänen $H$ et al. (2005): Estrogen and testosterone use different cellular pathways to inhibit osteoclastogenesis and bone resorption. J Bone Miner Res., 20:2224-32.

23. Nicholas G, Anastasia, Eugenia K et al. (2007): Markers of bone metabolism in eugonadal female patients with $\beta$-thalassemia major. Pediatric Hematology and Oncology, 24: 481-491.

24. Jensen C, Tuck S, Agnew J et al. (1998): High prevalence of low bone mass in thalassemia major. $\mathrm{Br}$ J Haematol., 103:911-5. 